Proc. of the XI Int. Conf. - Ion Implantation and other Applications of Ions and Electrons, Kazimierz Dolny 2016

\title{
Ion Beam Induced Surface Modification of ta-C Thin Films
}

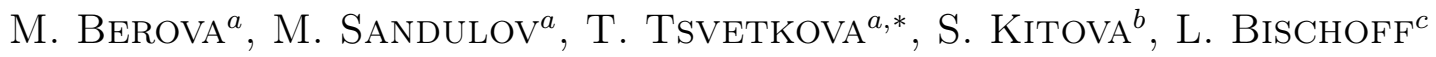 \\ AND R. BOETTGER ${ }^{c}$
}

${ }^{a}$ Institute of Solid State Physics, Bulgarian Academy of Sciences, 72 Tzarigradsko Chaussee, 1784 Sofia, Bulgaria

${ }^{b}$ Institute of Optical Materials and Technologies, Bulgarian Academy of Sciences,

109 Acad. G. Bontchev Str., 1113 Sofia, Bulgaria

${ }^{c}$ Institute of Ion Beam Physics and Materials Research, Helmholtz-Zentrum Dresden-Rossendorf, P.O.B. 5101 19, 01314 Dresden, Germany

Thin film samples $(d \approx 40 \mathrm{~nm})$ of tetrahedral amorphous carbon (ta-C), deposited by filtered cathodic vacuum arc, were implanted with $\mathrm{Ga}^{+}$at ion energy $E=20 \mathrm{keV}$ and ion fluences $D=3 \times 10^{14}-3 \times 10^{15} \mathrm{~cm}^{-2}$ and $\mathrm{N}^{+}$with the same energy and ion fluence $D=3 \times 10^{14} \mathrm{~cm}^{-2}$. The $\mathrm{Ga}^{+}$ion beam induced surface structural modification of the implanted material, displayed by formation of new phase at non-equilibrium condition, which could be accompanied by considerable changes in the optical properties of the ta-C films. The $\mathrm{N}^{+}$implantation also results in modification of the surface structure. The induced structural modification of the implanted material results in a considerable change of its topography and optical properties. Nanoscale topography and structural properties characterisation of the $\mathrm{Ga}^{+}$and $\mathrm{N}^{+}$implanted films were performed using atomic spectroscopy analysis. The observed considerable surface structural properties modification in the case of the higher fluence $\mathrm{Ga}^{+}$implanted samples results from the relatively high concentration of introduced $\mathrm{Ga}^{+}$atoms, which is of the order of those for the host element.

DOI: 10.12693/APhysPolA.132.299

PACS/topics: carbon, ion implantation, atomic force microscopy

\section{Introduction}

Amorphous carbon (a-C) is a disordered phase of carbon without long-range order, containing carbon atoms mostly in graphite-like $s p^{2}$ and diamond-like $s p^{3}$ hybridization sites. Depending on the relative concentrations of $s p^{2}$ - or $s p^{3}$ - hybridized carbon, a-C has shown excellent physical properties such as high hardness, low friction coefficient, chemical inertness, relatively high thermal conductivity, and optical transparency [1]. The term tetrahedral is used to describe amorphous carbon films with a large percentage of $s p^{3}$ bonding (up to $87 \%$ ). The films are manufactured using a variety of techniques, including filtered cathodic vacuum arc (FCVA), pulsed laser deposition (PLD), and mass selected ion beam deposition (MSIBD) [1-4]. The high $s p^{3}$ content in the films results in unique properties that include extreme hardness $(\approx 70 \mathrm{GPa})$, chemical inertness, high electrical resistivity, and wide optical band gap [5-9]. Other important factors which make the films an attractive material for coatings include a smooth surface and low friction, thermal stability and transparency over a wide spectral range. These properties also offer advantages as compared to another wide optical bandgap material - silicon carbide ( $\mathrm{SiC}$ ) - for uses in nanoscale optical data recording for archival information storage using focused ion beams (FIB) techniques, where $\mathrm{SiC}$ thin films found useful applications recently [10-17].

In the case of polycrystalline silicon carbide (pc-SiC) thin films, ion bombardment is used to amorphize areas

*corresponding author; e-mail: tsvet@issp.bas.bg of the films by computer operated FIB systems, thus creating useful optical contrast between non-irradiated polycrystalline areas and the irradiated amorphous areas, which can be further used for nanoscale optical data recording for archival information storage [10-12]. In the case of hydrogenated amorphous silicon carbide (a$\mathrm{SiC}: \mathrm{H})$ films, computer operated FIB systems are used to both introduce irradiation defects and additionally chemically modify the amorphous structure of the films, thus reducing their optical bandgap in even a more effective manner for the useful creation of optical contrast between implanted and non-implanted areas of the film material for applications in nanoscale optical data recording [13-17].

In both polycrystalline and amorphous $\mathrm{SiC}$ film materials, a considerable part in the creation of useful optical contrast between irradiated and non-irradiated areas of the films is played by the transformation of substantial part of the present diamond-like $\left(s p^{3}\right)$ carbon bonds, before the irradiation, into graphite-like $\left(s p^{2}\right)$ carbon bonds, as a result of it $[12,17]$. It is expected that a similar mechanism of the carbon bonds transformation would result when applying ion bombardment with different ions, e.g. gallium $\left(\mathrm{Ga}^{+}\right)$and nitrogen ions $\left(\mathrm{N}^{+}\right)$, in ta-C films, so that to achieve useful optical contrast between irradiated and non-irradiated areas of the films, which could possibly be of interest for further uses in archival information storage. Nanoscale topography and structural properties characterisation of the $\mathrm{Ga}^{+}$and $\mathrm{N}^{+}$implanted films has been performed using atomic spectroscopy analysis. 


\section{Experimental}

Thin ta-C films $(d \approx 40 \mathrm{~nm})$ were deposited on Corning glass substrates using a commercial FCVA system (Commonwealth Scientific Corporation). Carbon plasma is produced from the arc spot on the cathode, $99.999 \%$ pure graphite in high vacuum. Cathodic arcs are prolific generators of highly ionized carbon plasmas. With the FCVA technique, the plasma stream is steered through a magnetic filter to eliminate neutral particles generated at the cathode. At the filter exit, the fully ionized plasma, consisting of carbon ions and electrons, streams towards the substrate. The films were deposited at room temperature with an arc current of $120 \mathrm{~A}$ under floating conditions.

Ion implantation of $\mathrm{N}^{+}$and $\mathrm{Ga}^{+}$was carried out at room temperature (RT) using a commercial broadbeam ion implanter. The ion-beam intensity was $I \approx$ $2 \mu \mathrm{A} / \mathrm{cm}^{2}$, the ion energy was $E=20 \mathrm{keV}$, and the ion fluences used were $D=3 \times 10^{14}-3 \times 10^{15} \mathrm{~cm}^{-2}$ for $\mathrm{Ga}^{+}$implanted and $D=3 \times 10^{14} \mathrm{~cm}^{-2}$ for $\mathrm{N}^{+}$implanted samples. SRIM simulation program [18] was used to determine the projected range $R_{p} \approx 29 \mathrm{~nm}$ and the struggle $\Delta R_{p} \approx 10 \mathrm{~nm}$, for $\mathrm{N}^{+}$, and $R_{p} \approx 17 \mathrm{~nm}$ and $\Delta R_{p} \approx 4 \mathrm{~nm}$, for $\mathrm{Ga}^{+}$, implanted ions into the ta-C film samples $(d=40 \mathrm{~nm})$.

The surface topography and local morphology variations of implanted and unimplanted regions of the ta-C films were analysed with the help of atomic force microscopy (AFM) using scanning probe microscopy system (MFP-3DTM, Asylum Research, Oxford Instruments) operating in tapping and contact mode. All measurements reported here were performed at room temperature in an ambient air atmosphere.

\section{Results and discussion}

\subsection{Surface characterisation of $N^{+}$implanted ta- $C$ films}

The surface morphology of pristine ta-C samples was studied using AFM measurements in contact mode. In general, the films are homogeneous over large areas of the substrate (Fig. 1). RMS roughness is less than $2 \mathrm{~nm}$ at different areas of the sample.

The AFM analysis results for the $\mathrm{N}^{+}$implanted ta$\mathrm{C}$ samples showed again very low roughness, with only slight increase in the height of the implanted area (Fig. 2).

\subsection{Surface characterisation of $\mathrm{Ga}^{+}$implanted ta-C films}

The surface morphology of the $\mathrm{Ga}^{+}$implanted ta-C samples was studied using AFM measurements in tapping mode. As shown, the unimplanted films are homogeneous over large areas of the substrate (Fig. 3). The AFM analysis results for the $\mathrm{Ga}^{+}$implanted ta-C samples with the lower ion fluence showed again very low roughness, with only slight increase in the height of the

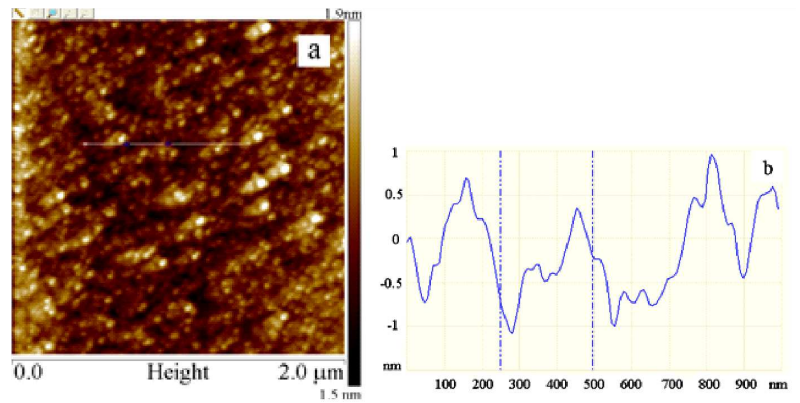

Fig. 1. AFM analysis of the pristine surface morphology of ta-C film: (a) topography and (b) surface roughness (RMS).
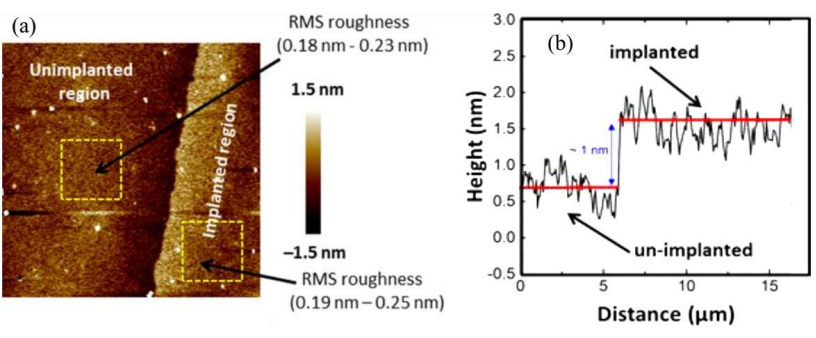

Fig. 2. AFM topography image (a) and height profile (b) across the boundary of an implanted and an unimplanted regions of a $40 \mathrm{~nm}$ thick ta-C film (implantation fluence $D=3 \times 10^{14} \mathrm{~cm}^{-2}$ ); Note that the AFM images are $10 \times 10 \mu \mathrm{m}^{2}$ in size.

implanted area; however, the surface height for the ta$\mathrm{C}$ films implanted with the higher $\mathrm{Ga}^{+}$fluence changes considerably (Fig. 4). Presumably, this is due to the high concentration of the introduced $\mathrm{Ga}^{+}$atoms, which is of the order of those for the host element. The change of the structures could lead also to changes in the optical properties, whose effect is a subject of some other publications of ours [19, 20].
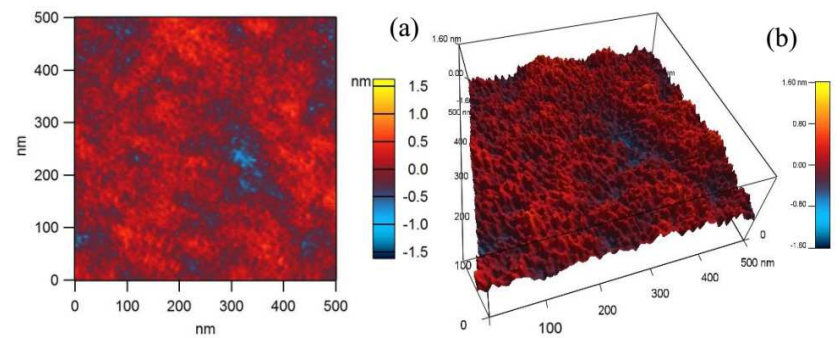

Fig. 3. AFM topography image (a) and height profile (b) across an unimplanted region in a $40 \mathrm{~nm}$ thick ta-C film. (note that the AFM images are $500 \times 500 \mathrm{~nm}^{2}$ in size).

\section{Conclusion}

The obtained results in the present work have shown that ion implantation of ta-C thin films with $\mathrm{N}^{+}$and $\mathrm{Ga}^{+}$ 

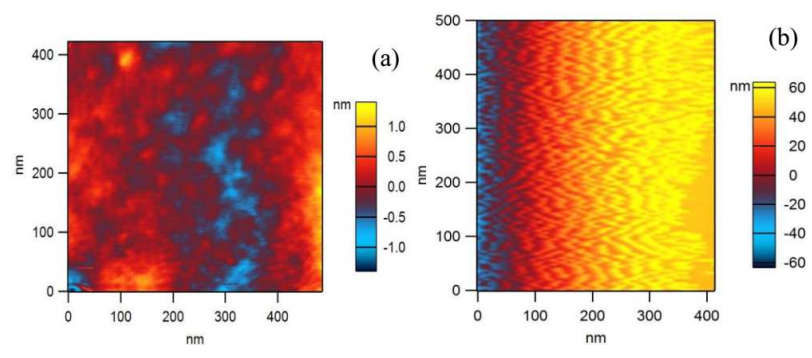

Fig. 4. AFM topography image of a $\mathrm{Ga}^{+}$implanted $40 \mathrm{~nm}$ thick ta-C film with implantation fluences $D_{1}=$ $3 \times 10^{14} \mathrm{~cm}^{-2}$ (a) and $D_{2}=3 \times 10^{15} \mathrm{~cm}^{-2}(\mathrm{~b})$. (note that the AFM images are $500 \times 500 \mathrm{~nm}^{2}$ in size).

with relatively low ion fluence $\left(D=3 \times 10^{14} \mathrm{~cm}^{-2}\right)$ has no significant effect on the film surface morphology. However, higher fluences of $\mathrm{Ga}^{+}$ion implantation (on the order of $D=3 \times 10^{15} \mathrm{~cm}^{-2}$ ) in such films results in considerable modification of the surface structure and morphology changes of the implanted ta-C films. The observed properties modification results from the high concentration of introduced $\mathrm{Ga}^{+}$atoms, which is of the order of those for the host element. The change of the structures could lead also to changes in the optical properties, studied in earlier publications of ours, whose effect could be made use of in high-density optical data storage.

\section{Acknowledgments}

The authors would like to thank the Operational Program "Development of the Competitiveness of the Bulgarian Economy", project BG16 1P0003-1.2.04-0034-C0001, for the financial support, and the group of Prof. S. Kitova for the samples preparation and characterisation. The authors would also like to thank the staff of the ion beam center at the Helmholtz-Zentrum DresdenRossendorf e.V., a member of the Helmholtz Association, for performing the ion implantation.

\section{References}

[1] A. Grill, Diam. Relat. Mater. 8, 428 (1999).

[2] D.R. McKenzie, D. Muller, B.A. Pailthorpe, Phys. Rev. Lett. 67, 773 (1991).

[3] P.J. Fallon, V.S. Veerasamy, C.A. Davis, J. Robertson, G.A.J. Amaratunga, W.I. Milne, J. Koskinen, Phys. Rev. B 48, 4777 (1993).
[4] T.A. Friedmann, K.F. McCarty, J.C. Barbour, M.P. Siegal, D.C. Dibble, Appl. Phys. Lett. 68, 1643 (1996).

[5] Y. Lifshitz, S.R. Kasi, J.W. Rabalais, Phys. Rev. Lett. 62, 1290 (1989).

[6] S.R.P. Silva, S. Xu, B.K. Tay, H.S. Tan, H.J. Scheibe, M. Chhowalla, W.I. Milne, Thin Solid Films 290291, 317 (1996).

[7] V.S. Veerasamy, J. Yuan, G. Amaratunga, W.I. Milne, K.W.R. Gilkes, M. Weiler, L.M. Brown, Phys. Rev. B 48, 17954 (1993).

[8] J. Robertson, Prog. Solid State Chem. 21, 199 (1991).

[9] S. Xu, D. Flynn, B.K. Tay, S. Prawer, K.W. Nugent, S.R.P. Silva, Y. Lifshitz, W.I. Milne, Philos. Mag. B 76, 351 (1997).

[10] B. Ruttensperger, G. Krötz, G. Müller, G. Derst, S. Kalbitzer, J. Non-Cryst. Solids 137-138, 635 (1991).

[11] G. Müller, Nucl. Instrum. Methods Phys. Res. B 8081, 957 (1993).

[12] S. Kalbitzer, Nucl. Instrum. Methods Phys. Res. B 218, 343 (2004).

[13] T. Tsvetkova, in: Beam Processing of Advanced Materials, Eds. J. Singh, S. Copley, J. Mazumder, ASM International, Metals Park 1996, p. 207.

[14] T. Tsvetkova, S. Takahashi, A. Zayats, P. Dawson, R. Turner, L. Bischoff, O. Angelov, D. DimovaMalinovska, Vacuum 79, 94 (2005).

[15] T. Tsvetkova, S. Takahashi, A. Zayats, P. Dawson, R. Turner, L. Bischoff, O. Angelov, D. DimovaMalinovska, Vacuum 79, 100 (2005).

[16] S. Takahashi, P. Dawson, A.V. Zayats, L. Bischoff, O. Angelov, D. Dimova-Malinovska, T. Tsvetkova, P.D. Townsend, J. Phys. D Appl. Phys. 40, 7492 (2007).

[17] T. Tsvetkova, P. Sellin, R. Carius, D. DimovaMalinovska, O. Angelov, J. Opto-electron. Adv. Mater. 9, 375 (2007).

[18] J.F. Ziegler, J.P. Biersack, U. Littmark, The Stopping and Range of Ions in Matter, Vol. 1, Pergamon, New York 1985.

[19] M. Sandulov, M. Berova, T. Tsvetkova, J. Phys. Conf. Ser. 558, 012044 (2014).

[20] M. Sandulov, M. Berova, T. Tsvetkova, J. Zuk, Acta Phys. Pol. A 128, 953 (2015). 